\title{
Female Genital Cut in Relation to Its Value and Health Risks among the Kisii of Western
} Kenya

\author{
Pauline G. Okemwa1, Harrison M. K. Maithya'2, David O. Ayuku ${ }^{3 *}$ \\ ${ }^{1}$ Department of Health Management, School of Public Health, Moi University, Eldoret, Kenya \\ ${ }^{2}$ Department of Anthropology, School of Arts and Social Sciences, Moi University, Eldoret, Kenya \\ ${ }^{3}$ Department of Behavioral Sciences, School of Medicine, Moi University, Eldoret, Kenya \\ Email: dayuku2000@yahoo.com
}

Received 22 June 2014; revised 9 August 2014; accepted 26 August 2014

Copyright (C) 2014 by authors and Scientific Research Publishing Inc.

This work is licensed under the Creative Commons Attribution International License (CC BY). http://creativecommons.org/licenses/by/4.0/

(c) (i) Open Access

\section{Abstract}

Background: The practice of female genital cutting as a cultural obligation is widespread in Kenya but there is little consensus about its effects on health. Some of the health risks associated with female genital cut range from minor and short-term to major and long-term effects including pain, bleeding, infections, and, in the extreme, death. Female genital cut is widespread among the Kisii but there is no adequate information about how it is currently practised and the value people attach to it. Objective: The objective was to establish the value of female genital cut as well as the health risks associated with the practice among the Kisii community of western Kenya. Methods: This was a cross-sectional study, which employed a mixed method approach to generate both quantitative and qualitative data. The quantitative data were obtained from a randomly selected sample of 373 respondents while quantitative data were generated from focus group discussions as well as key informants interviews. Results: The Kisii consider female genital cut a cultural identifier inherited from past generations and whose main value is a rite of passage from girlhood to womanhood. Majority (63\%) had heard of the health risks associated with female genital cut including transmission of infections, excessive bleeding and pain. But most of the community did not seem to know the long-term health consequences associated with female genital cut. Even though knowledge on the campaigns to eradicate the practice was found to be wide spread, the community's response toward the campaigns was less than positive. Conclusions: The authors conclude that female genital cut continues to persist in this community because of its value as a rite of passage, which currently has no substitute. This cultural demand by far outweighs the health risks associated with female genital cut, which are being mitigated through medicalization of the practice. For intervention programmes to succeed a more culturally sensitive campaign that is acceptable or appropriate alternative rite of passage is required.

*Corresponding author. 


\section{Keywords}

\section{Female Genital Cut, Value, Health, Culture, Kisii, Kenya}

\section{Introduction}

\subsection{Types of Female Genital Cut}

Female Genital Cut (FGC) also known as Female Circumcision (FC) is classified according to the nature of the practice. The World Health Organization (WHO) [1] identified four broad types or categories of FC ranging from Type I to IV. Type I is the excision of the prepuce with or without excision of part or the whole clitoris. Sunna or clitoridectomy falls under this category and this type of FGC is simple and less complicated compared to Types II, III, and IV. Type II is the excision of the prepuce and clitoris together with partial or total excision of the labia minora while Type III is the excision of part or all the external genitalia and stitching/narrowing of the vaginal opening (infibulation). Type IV is unclassified and includes pricking, piercing or incision of clitoris and/or labia, stretching of the clitoris and/or labia, and introduction of corrosive substances into the vagina to cause bleeding or herbs into the vagina to make it narrow or tighter.

Any type of FGC is harmful to women and may have immediate and/or long-term health, psychological, social, emotional, and economic consequences [2]. Indeed, the WHO estimates that in Africa alone about130 million girls and women suffer the physical and psychological effects of FGC [3].

\subsection{The Prevalence of Female Genital Cutting}

It is estimated that in Africa over 2 million girls are circumcised every year, which translates to 6000 genital cuts per day [3]. FGC is prevalent in 27 out of 46 Commonwealth African region countries [3]. In Kenya, FGC is practised in all the eight provinces and the prevalence ranges from $1 \%$ in Western Province to $98 \%$ in North Eastern Province [4]. Overall, 27\% of women in Kenya have undergone FGC. It is near universal among the Somali (98\%), the Kisii (96\%), and the Maasai (73\%) communities, and is significantly prevalent among the Embu (51\%), the Kalenjin (40\%), the Meru (40\%), and the Taita/Taveta (32\%). It is practised to a lesser extent by the Kamba (23\%), the Kikuyu (21\%), and to a much smaller extent by the Mijikenda/Swahili (4\%). FGC is almost non-existent among the Luo (0.1\%) and the Luhyia (0.2\%) communities [4].

Earlier research conducted among the Abagusii indicated that they continue to practice FGC to fulfill the community's customs and traditions that are deeply entrenched particularly among the older generation [5]. Most of the Abagusii also consider FGC a cultural identifier that distinguishes their daughters from the daughters of their Luo neighbors who do not circumcise their children [6].

For many decades there have been various efforts to eradicate FGC in Kenya and elsewhere in the world. The campaign against FGC has been entrenched in international conventions and declarations including those on human rights, women and children [7]-[10], which resulted in concrete actions such as the development of FGC manuals and policy guidelines [11] [12] including those developed by Kenya [13]. In Africa, the FGC eradication campaign includes the 1979 Khartoum seminar on Traditional Practices Affecting the Health of Women and Children [14], but there has been no consensus on the most appropriate approach to eliminate the practice [15].

In Kenya generally and Kisii in particular, the campaign against FGC has not been successful partly because those who advocate for its elimination began when their own daughters were already circumcised [16].

\subsection{The Context of FGC among the Kisii}

Among the Kisii community (also known as Abagusii) FGC is a cultural practice that is deeply rooted in tradition. Now, as in the past, and as is the case in many other African communities [11] [15] [17], FGC is mainly performed as a rite of passage from childhood to womanhood; once a girl undergoes FGC she is prepared for marriage. If the girl or woman has not undergone it, she is not prepared for life and is considered a disgrace in the community. The girl or woman who has not undergone FGC is not a right candidate for marriage and it is believed that she is cut off from the Kisii ancestors [16]. Thus among the Kisii the rite is a cultural identifier for their girls [6]. 
The initiatory ritual of FGC is more of a training than just a cut. The Kisii girl is instructed on how to behave before, during, and after the initiation. She is told the goodness and benefits of going through the rite, and is required not to cry, resist or try to stop the person carrying out the operation by holding her hand. Crying would invite evil spirits, which could haunt her in the future unless she is cleansed. In the period of seclusion, which traditionally is usually one to two months, the girl is trained about her sexuality and roles of a woman including looking after the husband, food preparation, preservation, cooking, house-keeping and child care. The sacred fire that is kept burning throughout the period of seclusion is meant to train the initiate that children once born are to be nurtured. It is taboo for the sacred fire to go out. The going out of the fire is believed to result in barrenness [18]. Traditionally, when the young girl comes out of seclusion she is bathed, decorated and ornamented with earrings, necklace, armlets, bracelets, dressed, and anointed and the initiate now graduates into adulthood. The ceremony is normally accompanied by dancing, pomp, splendor, singing, eating and drinking.

FGC is surrounded by several myths and beliefs. For example, it is believed that uncircumcised women are likely to have still births, or their children would die before they reach maturity. A girl who has not undergone the rite will have difficulty finding a man to marry her, the clitoris could grow long and have many branches that would not allow sexual intercourse [16] thereby interfering with marriage, fertility, family, and community life.

FGC is performed in order to conform to societal demands and expectations, so as not to be seen as an outcast or deviant in the society [2] [19]. But FGC has taken another dimension since most communities, which now perform it keep it secret. Most service providers assume FGC is declining, while some authors feel that the practice has actually gone underground and it is now performed in secret [6] to avoid reprisals from government agencies. In communities where the prevalence rate of FGC is considered to have gone down, the main reason given for the drop is change of environment, behaviour and attitude [16], which may not necessarily be the case.

Research carried out in Kenya has only illuminated the trends in prevalence rates, types of female genital cut, how it is done and by whom, the social-cultural significance and accompanying beliefs as well as the physical health effects but with little focus on the serious long term health implications of FGC.

FGC raises several issues including health, psychological and physical trauma. As a cultural practice FGC has different meanings and value for the communities that practice it [17] [20] including the Kisii [18]. The ireversible health effects caused by FGC to women include health complications, which range from, shock, emotional disturbance, bleeding, acute urine retention, dysfunction, to the risk of HIV/AIDS infection, and death [21] [22].

Studies of FGC among the Kisii show that they practise Type I and various authors have looked at different aspects of this practice. Gwako [19] examined continuity and change in the practice of clitoridectomy while Mose [23] investigated the impact of FGC on the role of women, yet others have described how the operation is carried out. Njue and Askew [6] focused on the medicalization of FGC among the Abagusii, and Akama and Maxon [18] have looked at the value of FGC in this community. However, none of these studies adequately examine and present FGC as it is currently practised. And generally, in spite of the medicalization of FGC, the way the operation is performed may have serious health consequences. This paper discusses the value of FGC and its perceived attendant health risks among the peri-urban and rural Kisii of western Kenya. The aim is to provide evidence that can be used to implement culturally appropriate interventions intended for behaviour change.

\section{Material and Methods}

\subsection{Study Area and Design}

The study on which this paper draws was carried out among the Kisii of western Kenya from August to November, 2008. It was a cross-sectional survey study design and was conducted in Bosongo Location of Kiogoro Division of Kisii Central District.

The seven divisions in Kisii Central District were listed in order of size in $\mathrm{km}^{2}$ then the Kiogoro Division $\left(61.3 \mathrm{~km}^{2}\right)$ was purposive selected. This was based on the researchers' need to obtain a manageable but adequate sample size and also because the dominant population is Kisii who were the focus of this study. The three locations of Kiogoro Division were then listed indicating the distance from Kisii municipality. These are Kiogoro Location with a total population of 20,037, Kegati with 15,945, and Bosongo with a total population of 25,921 [24]. Kiogoro and Kegati locations are each three kilometers away from the municipality and were eliminated and Bosongo Location, which has more than three quarters of its sub-locations (smaller administrative units) 
within Kisii Municipality selected. Bosongo borders Township Location to the North, Kegati Location to the South, Bogiakumu Location to the North-West, and Kiogoro Location to the South-West. Bosongo comprises three sub-locations namely Bobaracho (population 6854), Nyanchwa (population 6841), and Nyaura (population 12,226) giving a total population of 25,921 in near equal proportions of males and females [25]. This method of selection was necessary in order to include Kisii Level 5 District Hospital (which is located in Bosongo) for the purpose of sampling health workers to provide pertinent information.

\subsection{Sampling and Sample Size}

The sample size required for the study was determined by using a 95\% confidence level and a sample error of 5\% using the Fishers Exact formula:

$$
n=\frac{z^{2}(p q)}{d^{2}}
$$

where, $n$ is the sample size;

$z$, is the $z$-score corresponding to $95 \%$ confidence interval $=1.96$;

$d$, is the amount of discrepancy allowed $=0.0173$;

$p$, is prevalence of circumcision $=0.97$;

$q=0.03$.

The sample was proportionately distributed using the formula below:

Sub-location population $\times$ sample size divide by the location population.

Stratum I = Bobaracho

$$
n_{1}=\left(\frac{6.854}{25.921}\right) \times 373=99
$$

Stratum II = Nyanchwa

$$
n_{2}=\left(\frac{6.841}{25.921}\right) \times 373=98
$$

Stratum III = Nyaura

$$
n_{3}=\left(\frac{12.226}{25.921}\right) \times 373=176
$$

Therefore, $n=n_{1}+n_{2}+n_{3}=373$.

With the help of village elders and research assistants, a complete list of all households in each of the three sub-locations was prepared. Each household was given a unique identifier and a sampling fraction calculated. Systematic sampling was used to select households in the sub-locations. The first case was identifies by simple random sampling, which would start at a random point between 1 and 7 then eligible members in every $7^{\text {th }}$ household would be selected for questionnaire administration, each at a time. This process was repeated until the desired sample was reached.

The inclusion criteria were: those born in the area and are residents of Bosongo Location, those aged 15 years and above, and men who were married. The assumption was that these respondents had seen or experienced the effects of FGC and would also be informed of its value. Similarly, they were expected to have information on the challenges facing campaigns against FGC. The exclusion criteria were: residence outside the location and, for males, unmarried. It was assumed that the unmarried males did not know either the value of FGC or its health effects.

Purposive sampling was used to select key informants who were persons endowed with information regarding community values and health related issues. They included government administrators such as assistant chiefs, religious leaders, village and clan elders, aged men and women, health service providers such as medical personnel including nurses, clinical officers and hospital/nursing assistants as well as traditional health service providers such as traditional birth attendants (TBAs) and/or circumcisers (community own resource persons). In order to make use of group dynamics to gain greater insights into FGC, 8 FGDs each with between 6 - 12 par- 
ticipants covering both men and women of various age groups were purposively selected from the community and constituted. Participants were selected from among village elders who assist the chiefs in resolving social issues within their villages, TBAs, organized women groups, and community health workers.

\subsection{Data Collection Methods and Tools}

Both quantitative and qualitative data were collected. Survey was used to collect quantitative data by use of a structured questionnaire tool prepared by the research authors and administered to a total sample of 373 respondents women and married men aged between 15 and 100 years within the community. The questionnaire tool was pre-tested with a smaller sample before commencement of the study. The pilot study was conducted in Mosocho sub-location, an area with a population which had similar characteristics as the actual study area. Based on the pre-test, questions that were ambiguous were re-phrased and adjustments made on the sequence and flow of the questions in the questionnaire.

Qualitative data were collected through observational methods, face to face interviews including key informant interviews (KIs), and focus group discussions (FGDs). An interview guide tool was developed and used to obtain data from KIs. Similarly, an interview guide based on themes around FGC, its value and health effects was used in FGD discussions. To create an open atmosphere conducive to free discussions, the groups were categorized according to age, gender and occupation/profession. With the permission of the informants/participants a tape recorder was used as a tool for recording the discussions with KIs and FGDs. participants.

Unstructured observation of behaviors, actions, activities, and interactions was used as a method for understanding more fully the practice of FGC. Data were obtained through watching and hearing. The female researcher in the team made direct observations by visiting two households where the FGC operation was being conducted.

\subsection{Data Analysis}

Quantitative data were coded and entered into SPSS program. The software was used to generate Univariate statistics such as frequencies, percentages, and measures of central tendency and dispersion, and Bivariate statistics. These data are presented using tables, percentages, and pie charts. Chi-square test was performed to compare relationship between selected variables.

Qualitative data captured through tape-recording of discussions were thoroughly checked at the time of play back without disrupting the original flow of the information. These data were transcribed, synthesized, interpreted and presented as quotations and narratives according to various study themes. Observational data supported validated the reported behavior.

\subsection{Ethical Considerations}

Before embarking on data collection, approval of the study was obtained from the Institutional Research and Ethics Committee (IREC) of the School of Medicine and Public Health at Moi University. Permission was sought from the office of the District Officer Kiogoro Division to conduct the study within the area. The study was explained to the participants and with few clarifications, they agreed to participate in the study and consented by signing the consent form that had been prepared. Participation in the study was voluntary and respondents had an option of withdrawing from the study at any stage. Confidentiality of the informants and data was strictly adhered to.

\section{Results}

\subsection{Sociodemographic Characteristics}

Table 1 presents a summary of the distribution of respondents' selected backgrounds characteristics.

The majority (77\%) of the respondents were in the groups of between ages 15 - 44 years. The minimum age of respondents was fifteen years, which suggests that customarily, Kisii girls marry at a fairly young age.

Churches have been used as platforms for disseminating information aimed at eradicating FGC. So it was important to establish the religious affiliation of the respondents. This is relevant when assessing the influence of religion on campaigns against FGC. The majority of people in the study community belong to either Catholic or 
Table 1. Distribution of the respondents by background characteristics.

\begin{tabular}{|c|c|c|c|}
\hline \multicolumn{2}{|c|}{ Characteristics } & \multirow{2}{*}{$\begin{array}{c}\text { Frequency } \mathbf{N}=\mathbf{3 7 3} \\
107\end{array}$} & \multirow{2}{*}{$\begin{array}{c}\text { Percentage (\%) } \\
28.7\end{array}$} \\
\hline \multirow{5}{*}{ Age of respondent } & $15-24$ & & \\
\hline & $25-34$ & 90 & 24.1 \\
\hline & $35-44$ & 90 & 24.1 \\
\hline & $45-54$ & 45 & 12.1 \\
\hline & $>55$ & 41 & 11.0 \\
\hline \multirow{3}{*}{ Gender } & Male & 125 & 33.5 \\
\hline & Female & 248 & 66.5 \\
\hline & $\mathrm{RC}$ & 175 & 46.9 \\
\hline \multirow{4}{*}{ Religion } & SDA & 146 & 39.1 \\
\hline & Protestant & 45 & 12.1 \\
\hline & Muslim & 3 & 0.8 \\
\hline & ATRs & 4 & 1.1 \\
\hline \multirow{4}{*}{ Education } & Less than Primary & 36 & 9.7 \\
\hline & Primary & 115 & 30.8 \\
\hline & Secondary & 155 & 41.6 \\
\hline & University/college & 67 & 18.0 \\
\hline \multirow{4}{*}{ Occupation } & Self Employed & 166 & 44.5 \\
\hline & Employed & 58 & 15.5 \\
\hline & Not Employed & 119 & 31.9 \\
\hline & Student & 30 & 8.0 \\
\hline
\end{tabular}

Seventh Day Adventist faiths, which combined accounted for 86\% ( $n=321)$ of the respondents. Literature on FGC suggests that the practice has considerably reduced in communities where education levels are high. Similarly, it has been argued that the practice has reduced in communities with high income/economic levels, which is also closely associated with education. It was, therefore, necessary to capture the respondents' level of education in order to establish whether a higher level of education has any contribution towards the value attached to FGC or its practice. The respondents had reasonable levels of education: a large number (42\%) had attained secondary education while a significant percentage (18\%) had university education. Only a small number (16\%) was on formal full time employment.

The socio-demographic data were used to give a general picture of the study population but also provided specific variables relevant in analysing the community's values, knowledge, attitude and practices relating to FGC.

\subsection{The Prevalence of FGC}

The prevalence of FGC within the study population was found to be universal, with 99.2\% being circumcised or reporting knowledge of a woman who had undergone the cut. This is higher than the prevalence of FGC reported in 2008-2009 KDHS, which was 96\% [4]. Village and clan elders reported that FGC had gone underground because those who perform it or allow their daughters to be circumcised risked arrest by government agents. FGD participants stated that FGC is a must among the Abagusii and that women may be socially stigmatized by the community if they are not cut. Cutting may be performed even at the time a woman is giving birth. One clan elder asserted: 
"Women married to Kisii men from communities that do not circumcise their girls, as is the case with the Luo and Luhyia, must undergo the cut before they are accepted in the community. They are circumcised at the time of giving birth either with or without their knowledge."

It was clear from FGDs with health care providers that uncircumcised girls are stigmatized. A nurse had to have her daughters cut. She stated that:

"I had to take my daughters to be cut because they were being ridiculed by my family. They derogatory referred to my daughters as 'sister's uncircumcised girls'. This kind of reference went on until I felt it was too much and I had to have them undergo the cut to avoid the stigma."

The foregoing testimony shows that family pressure and cultural demands override professional affiliation and knowledge on health risks associated with FGC.

\subsection{Origin and Value of FGC}

The question on the origin of female genital cut elicited diverse responses as shown in Table 2.

FGC is a traditional rite that has been handed down from generation to generation. Data from FGDs were in agreement with the foregoing with most participants saying that they found the practice in existence. Some said that FGC was used to "treat" excessive sexual desire, while others thought it was intended to control enlarged clitoris, erection of the clitoris, and a diseased clitoris. Table 3 presents data on the role and value of FGC.

The main value of FGC is that it is a rite of passage although a significant number thought it is intended to control female sexuality. A female FGD participant succinctly captures the foregoing, thus:

"Female circumcision reduces sexual desire, what we remove is called the clitoris (egesono or egetongoche)... that is what we cut. The clitoris has the woman's sexual desire (esono), therefore, when some part of the clitoris is removed... when it is removed that high sexual desire in a woman comes down."

A male key informant concurred with the notion of sexual control, by stating that:

"The main reason for removing the clitoris is to prevent women from engaging in prostitution or desire for more than one man. If the clitoris is removed, even if the husband goes away for a long time, she remains faithful until the husband comes back home.”

A small number (14\%) but indicative of cultural change thought that in the present times FGC has lost value and meaning as it is a rite performed without ritual.

Table 2. Origin of female genital cut among the Abagusii.

\begin{tabular}{ccc}
\hline Origin of FGC & Frequency $\mathbf{~}=\mathbf{3 7 3}$ & Percentage (\%) \\
\hline Biblical & 117 & 31.4 \\
Don't Know & 13 & 3.5 \\
Culture & 234 & 62.7 \\
Mark of Identity & 6 & 1.6 \\
Male Circumcision & 1 & 0.3 \\
Lower Sex Desire & 2 & 0.5 \\
Total & $\mathbf{3 7 3}$ & $\mathbf{1 0 0 . 0}$ \\
\hline
\end{tabular}

Table 3. Value of FGC among the Kisii.

\begin{tabular}{ccc}
\hline Significance & Frequency N = 373 & Percentage (\%) \\
Rite of Passage & 188 & 50.4 \\
Reduce Sex & 89 & 23.9 \\
Disease Control & 44 & 11.8 \\
No Value & 52 & 13.9 \\
Total & $\mathbf{3 7 3}$ & $\mathbf{1 0 0 . 0}$ \\
\hline
\end{tabular}


In terms of the role played by FGC in the socialisation and development of young girls, Figure 1 presents data on lessons given to the initiates.

The value of FGC is in the training of the initiates on various responsibilities that they are expected to undertake in the future and when they move from girlhood to womanhood. The training includes sexual and wifery responsibilities such as how to look after the husband, cooking, cleaning, child care, self respect, and responsible relationships. Thus FGC is central to the Kisii culture and prepares the initiate for life in marriage as further evidenced by the following female FGD participant:

"The girl is trained on how to handle a man in marriage... Once the seclusion period is over, the girl is ready for womanhood and has been prepared for marriage... But the Abagusii do not marry their daughters immediately after circumcision. The girl is usually trained by the old mothers (grandmothers) on how they will begin their marriage life."

\subsection{Knowledge of the Health Risks Associated with FGC}

The respondents were asked if they had heard or knew of any health risks associated with FGC. While the majority had heard of the health risks associated with FGC, a significant $37 \%(n=137)$ had never heard of any health effects associated with the cut. The respondents were further asked to state the health risks of FGC that they knew and their responses are displayed in Table 4.

Combined, about $61 \%$ knew of a health risk associated with FGC. This is interesting because, in spite of this knowledge and as indicated earlier, FGC is universal in the Kisii community. Significantly, however, there is a sizeable number (23\%) who do not associate FGC with any health risks.

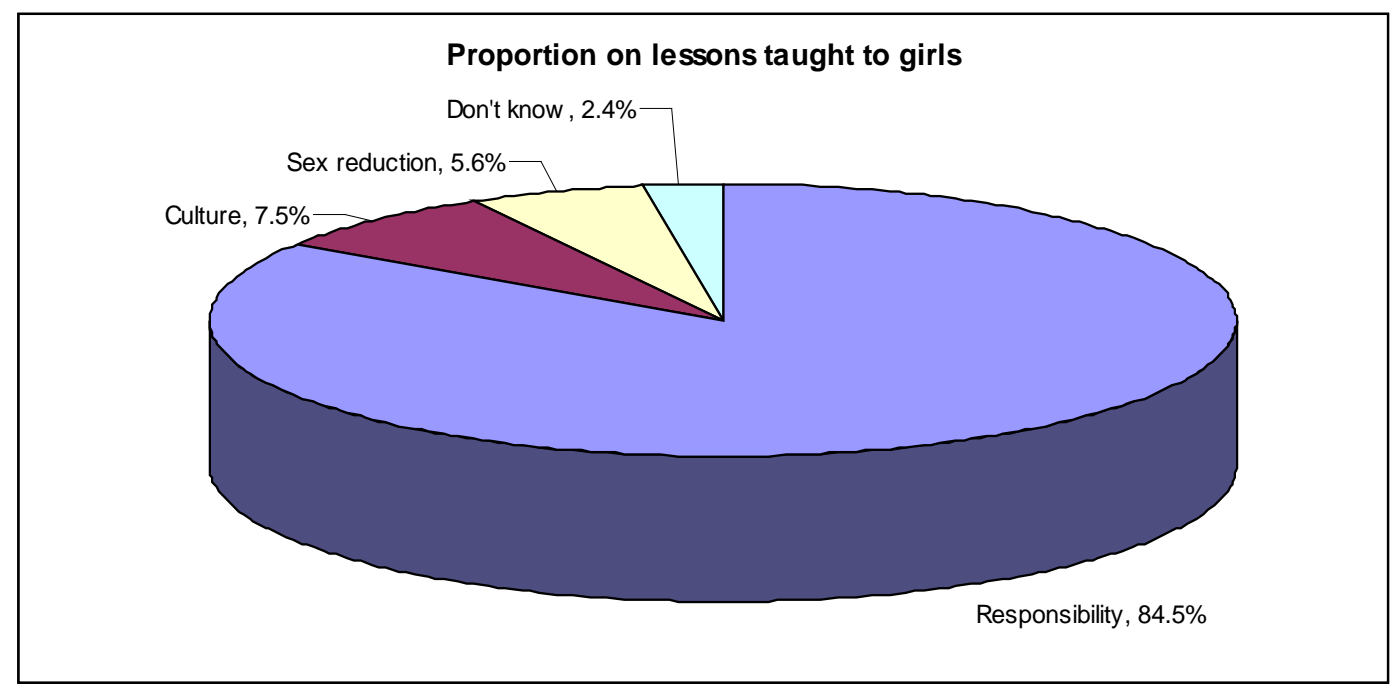

Figure 1. Proportion on lessons given to girls.

Table 4. Knowledge of health risks associated with FGC.

\begin{tabular}{ccc}
\hline Health Risks & Frequency N = 373 & Percentage (\%) \\
\hline Disease Transmission & 126 & 33.8 \\
Profuse Bleeding & 67 & 17.9 \\
No Answer & 61 & 16.4 \\
Death & 7 & 1.9 \\
Difficult Labor & 27 & 7.2 \\
None & 85 & 22.8 \\
Total & 373 & 100.0 \\
\hline
\end{tabular}


FGDs data corroborated the foregoing by showing that the main health risks resulting from FGC are the spread of diseases, mainly HIV/AIDS through the use of contaminated circumcision equipments. However, if the circumcisers use clean tools, then FGC was deemed to be safe. But also it was felt that the health risks associated with the cut are complex and are experienced much later in life. In one FGD comprising elderly men it was noted that when women are above the age of 50 years, their sexual desire reduces and this causes problems in families, for example, separation or divorce. One participant put it thus:

"At the age of 50 and above, women tend to completely lose desire for men, and that could be the main reason why most men have 'blockage' (meaning prostate cancer). We need to be 'serviced', but at times we are put off by our own wives because they were cut, and the desire for sex was killed."

The health workers interviewed reported that medical complication during child birth is not uncommon with circumcised women. A female nurse observed:

"Vaginal tearing is common during child delivery. The organ is made in such a way that it should expand. In some cases the mama (woman) who is delivering must be opened... if there is no cut there will be a tear... but not for all women... However, at least over $70 \%$ experience of tearing... definitely there is excessive pain and at times prolonged labor."

A nurse working in the labor ward reported that in the preceding one year she had witnessed 4 serious cases of obstructed labor during delivery. This difficulty she attributed to circumcision.

However, some traditional birth attendants (TBAs) argued that there was no labor obstruction as a result of FGC. According to them obstruction depends on the physiology of the woman. The following argument was captured:

P1 There is no difficulty in child delivery because of the cut. The difficult labor results from the woman's body structure.

P2 The size of the bones will determine the way the child will come out. If we compare the circumcised Abagusii and the uncircumcised Luo (Luos are Kisii neighbors)...

$\mathrm{P} 4 \mathrm{We}$ are reporting from experience...

P2 The cases we have witnessed both at home and in the labor wards, the Luos suffer more than the Abagusii (TBAs).

However, some TBAs observed that FGC has health effects depending on how the operation is carried out and the age of the initiate, a finding that is in consonance with data from FGDs in which some held that the younger the initiate, the safer she would be. A community circumciser had the following to say:

"It depends on the age, the method and the practitioner. The older ones are at a risk of excessive bleeding. Otherwise, if circumcised at an early age it has no effect... the Abagusii do not perform the excessive cutting, we only prick to remove bad blood. When untrained people perform the operation, then it will be dangerous... these days a different blade is used for each initiate to avoid transmission of diseases through contaminated tools."

Indeed, majority of the girls are circumcised before they reach age 10, and by 15 years all of them are circumcised.

When they were asked if they knew the persons who perform FGC, 64\% $(n=240)$ mentioned medical personnel; a significant number of the operations were carried out by traditional circumcisers $(31 \%=114)$. Even though most FGCs are performed by medical personnel implying that the rite has been medicalized, a large number, $77 \%(n=289)$ was not given any medication after the cut. Additionally, in about $69 \%(n=256)$ of the operations were performed while the initiates were either sitting on a stone or stool suggesting that the operations were done at home.

\subsection{Campaigns against FGC}

An overwhelming majority knew of campaigns against FGC as shown in Table 5.

Those who reported support for the eradication of FGC did so because of health concerns $(53 \%=197)$, some because of concerns for low sex desire $(8.0 \%=30)$ or government order $(4.6 \%=17)$.

\subsection{Community Attitudes towards FGC}

The community's attitude towards uncircumcised women was assessed in order to establish the value of FGC among the Kisii. The respondents were asked whether they knew of girls of marriageable age in the community 
who were uncircumcised and none knew of any suggesting the universality of the rite. They were further asked whether they would socialize with an uncircumcised woman and nearly all of the respondents said they would not.

In order to further assess the place of FGC in the community, the respondents were asked whether they knew of any girl/woman who failed to marry because she was not circumcised and only $7 \%$ knew of a case. Indeed 57\% of all male respondents said they were not willing to marry an uncircumcised girl. This implies circumcision is an important rite of passage to womanhood and family life.

Female circumcision remains central to the life of the Abagusii as evidenced by the following observations by a male FGC participant:

"Since the anti FGC campaigns started, the uncircumcised girls no longer have respect for their parents. They are not restrained from doing wrong... your daughter can disappear from home until the next day. This behaviour never used to exist...”

Another FGD participant contributed:

"The mode of dressing is another issue. Girls are not taught how they should dress. They wear very short and tight clothes, and trousers are freely worn by women. The girls do not recognize and respect their fathers or their fathers-in-law. They wear cloths exposing the stomach... respect has been eroded away. In the old days if girls heard their father coming they could hide for fear of being found 'naked', but these days they walk scantly dressed."

It was stressed that it was difficult for the older generation to stop FGC.

The older generation will never do away with female circumcision. May be the best approach is to educate the younger generation. Then after our generation is gone the practice may stop.

We generally sought to know the relevance of female circumcision and the responses are displayed in Table 6.

Overall, 62\% find FGC relevant. A smaller but significant number (38\%) consider the practice irrelevant or outdated, which points to the changing or diminishing value of FGC.

\subsection{Observations on the Rite of FGC}

The female member of the research team had an opportunity to observe FGC being performed. Case 1 below highlights the people involved in this rite.

\subsection{Case 1}

This case involved a girl aged 9 years and the circumciser was a retired nurse. The mother of the girl was a high school teacher. The girl was made to sit on a flat stone and was blindfolded by a woman who sat flat on the

Table 5. Knowledge of FGC eradication campaigns.

\begin{tabular}{ccc}
\hline Knowledge & Frequency & Percentage \\
\hline Yes & 348 & 93.3 \\
No & 25 & 6.7 \\
Total & $\mathbf{3 7 3}$ & $\mathbf{1 0 0 . 0}$ \\
\hline
\end{tabular}

Table 6. Respondents' opinion on the relevance of FGC.

\begin{tabular}{ccc}
\hline & Frequency $\mathbf{~}$ & Percentage (\%) \\
\hline Very relevant & 75 & 20 \\
Relevant & 157 & 42 \\
Irrelevant & 100 & 27 \\
Outdated & 41 & 11 \\
Total & 373 & 100.0 \\
\hline
\end{tabular}


ground that the girl's back rested on her chest. With her legs wide open the nurse cut off the tip of the clitoris using a surgical blade. After cutting the nurse applied medicine on the cut area in order to prevent excessive bleeding. She also gave the girl antibiotics to prevent infection. The ceremony was meant to not attract attention for fear of arrest by authorities so it was not publicized. It was attended by few people and silently conducted without singing or dancing as is usually the case. The members present shared food and drinks. The girl, together with other initiates, was secluded and a sponsor assigned to them to provide the necessary training as they recuperated.

The people involved in this case were a health professional and a well educated mother. Education and occupation do not thus necessarily positively impact FGC. The use of health professionals and application of medicine also implies that FGC has been medicalized, thereby making it a bit safe.

\subsection{Chi-Square Test on FGC}

Chi-square test was performed to determine the relationship between various independent variables, which were age of the respondents, gender, religious affiliation, levels of education and occupation, and the dependent variables, which were value of FGC, health risks associated with FGC, and its eradication campaigns. The cross tabulated chi-square test results are presented in Table 7 and Table 8.

Table 7. Distribution of responses on value of FGC by background characteristics.

\begin{tabular}{|c|c|c|c|c|c|c|c|}
\hline Factors & $\begin{array}{c}\text { Rite of Passage } \\
\text { N (\%) }\end{array}$ & $\begin{array}{c}\text { Reduce Sex } \\
\text { N (\%) }\end{array}$ & $\begin{array}{c}\text { Disease Control } \\
\text { N (\%) }\end{array}$ & $\begin{array}{c}\text { No Value } \\
\text { N (\%) }\end{array}$ & Total & $\mathrm{X}^{2}$ & p-Value \\
\hline \multicolumn{8}{|l|}{ Age of Respondents } \\
\hline $15-24$ & $40(37.3)$ & 34 (31.9) & $16(14.9)$ & 17 (15.9) & 107 & & \\
\hline $25-34$ & $48(53.3)$ & $23(25.6)$ & $9(10.0)$ & $10(11.1)$ & 90 & 33.706 & 0.001 \\
\hline $35-44$ & $56(62.2)$ & $20(22.2)$ & $3(3.3)$ & $11(12.2)$ & 90 & & \\
\hline $45-54$ & $23(51.1)$ & $8(17.8)$ & $11(24.4)$ & $3(6.7)$ & 45 & & \\
\hline $55>$ & $21(51.2)$ & $4(9.8)$ & $5(12.1)$ & $11(26.9)$ & 41 & & \\
\hline \multicolumn{8}{|c|}{ Gender of Respondents } \\
\hline Male & $82(65.6)$ & $18(14.4)$ & $10(8.0)$ & $15(12.0)$ & 125 & 18.473 & 0.000 \\
\hline Female & $106(42.7)$ & $71(28.6)$ & 34 (13.7) & $37(15.0)$ & 248 & & \\
\hline \multicolumn{8}{|c|}{ Religion of Respondents } \\
\hline Roman Catholic & $91(55.0)$ & 37 (21.1) & 19 (10.9) & $28(16.0)$ & 175 & & \\
\hline SDA & $72(49.3)$ & $41(28.0)$ & $16(11.1)$ & 17 (11.6) & 146 & 21.473 & 0.044 \\
\hline Protestant & $23(51.1)$ & $10(22.2)$ & $9(20.0)$ & $3(6.7)$ & 45 & & \\
\hline Muslim & $1(33.3)$ & $1(33.3)$ & $0(0.0)$ & $1(33.3)$ & 3 & & \\
\hline ATRs & $1(25.0)$ & $1(25.0)$ & $0(0.0)$ & $2(50.0)$ & 4 & & \\
\hline \multicolumn{8}{|c|}{ Education of Respondents } \\
\hline Less Primary & $18(50.0)$ & $2(5.6)$ & $9(25.0)$ & $7(19.4)$ & 36 & & \\
\hline Primary & 59 (51.3) & $31(27.0)$ & $13(11.3)$ & $12(10.4)$ & 115 & 23.869 & 0.005 \\
\hline Secondary & 68 (43.9) & $40(25.8)$ & 20 (12.9) & 27 (17.4) & 155 & & \\
\hline University/College & $43(70.5)$ & $10(16.4)$ & $2(3.3)$ & $6(9.8)$ & 61 & & \\
\hline \multicolumn{8}{|c|}{ Occupation of Respondents } \\
\hline Self Employed & $84(50.6)$ & $46(27.8)$ & $18(10.8)$ & 18 (10.8) & 166 & & \\
\hline Employed & 34 (58.6) & $13(22.4)$ & 7 (12.1) & $4(6.9)$ & 58 & & \\
\hline Not Employed & $55(46.2)$ & $24(20.2)$ & $14(11.8)$ & 26 (21.8) & 119 & 12.430 & 0.190 \\
\hline Student & $15(50.0)$ & $6(20.0)$ & $5(16.7)$ & $4(13.3)$ & 30 & & \\
\hline
\end{tabular}


Table 8. Distribution of responses on knowledge of health risks associated with FGC by background characteristics.

\begin{tabular}{|c|c|c|c|c|c|}
\hline Factors & Yes N (\%) & No $\mathbf{N}(\%)$ & Total & $\mathrm{X}^{2}$ & p-Value \\
\hline \multicolumn{6}{|l|}{ Age of Respondents } \\
\hline $15-24$ & $61(57.0)$ & $46(43.0)$ & 107 & & \\
\hline $25-34$ & $63(70.0)$ & $27(30.0)$ & 90 & & \\
\hline $35-44$ & $63(70.0)$ & 27 (30.0) & 90 & 28.309 & 0.000 \\
\hline $45-54$ & $36(80.0)$ & $9(20.0)$ & 45 & & \\
\hline $55>$ & $13(31.7)$ & $28(68.3)$ & 41 & & \\
\hline \multicolumn{6}{|l|}{ Gender of Respondents } \\
\hline Male & $84(67.2)$ & $41(32.8)$ & 125 & 1.249 & 0.264 \\
\hline Female & $152(61.9)$ & $96(38.1)$ & 248 & & \\
\hline \multicolumn{6}{|l|}{ Religion of Respondents } \\
\hline RC & $102(58.3)$ & $73(41.7)$ & 175 & & \\
\hline SDA & $104(71.2)$ & $42(28.8)$ & 146 & 7.259 & 0.123 \\
\hline Protestant & $25(55.6)$ & $20(44.4)$ & 45 & & \\
\hline Muslim & $2(66.7)$ & $1(33.3)$ & 3 & & \\
\hline No Religion & $3(75.0)$ & $1(25.0)$ & 4 & & \\
\hline \multicolumn{6}{|c|}{ Education of Respondents } \\
\hline Lower than Primary & $13(34.3)$ & $23(65.7)$ & 36 & & \\
\hline Primary & $56(48.7)$ & 59 (51.3) & 115 & 45.926 & 0.000 \\
\hline Secondary & $106(68.4)$ & 49 (31.6) & 155 & & \\
\hline University/College & $61(91.0)$ & $6(9.0)$ & 67 & & \\
\hline \multicolumn{6}{|c|}{ Occupation of Respondent } \\
\hline Self Employed & $98(59.0)$ & $68(41.0)$ & 166 & & \\
\hline Employed & $47(81.0)$ & $11(19.0)$ & 58 & 13.396 & 0.004 \\
\hline Not Employed & $68(57.1)$ & $51(42.9)$ & 119 & & \\
\hline Student & $23(76.7)$ & $7(23.3)$ & 30 & & \\
\hline
\end{tabular}

Over 50\% of all respondents age 25 years and above felt that FGC is a rite of passage. More males (66\%) compared to women (43\%) felt that FGC is a rite of passage implying that men are keen to hold on to the rite. Responses by religion of the respondents show that the value of FGC as a rite of passage is significantly held across the major religious affiliations. Almost a similar trend is reflected in the age of the respondents with responses that are over $50 \%$ for all the age categories. Likewise responses based on the level of education of the respondents and FGC were more than 50\% apart from those with secondary education. All responses by occupation were also over $50 \%$, with the exception of not employed. The chi-square test indicates that there is association between age, gender, religion, education of the respondents at $\mathrm{p}<0.05$. The general conclusion is that the various background characteristics did not significantly affect information regarding FGC as the knowledge/information is spread almost equally on the selected variables in the community. Table 8 presents data on knowledge of FGC health risks against background variables.

The responses show that the community knows the health risks associate with the FGC as displayed in Table 8. Most background characteristics have scores that are above 50\%. Only respondents aged 55 years and above and those with lower than primary level education recorded 32\% and 34\% respectively. Thus the chi-square test 
on the knowledge of the health risks associated with FGC at $\mathrm{p}<0.05$ show that there is association with age of respondents, education, and occupation

Chi square test at $\mathrm{p}<0.05$ show that there is no association between the background characteristics and the response towards FGC eradication campaigns. Indeed, the community's response towards campaigns against FGC is largely less than positive

\section{Discussion}

The current study reveals that FGC is mainly a cultural practice with diverse sociocultural value. The majority of people consider the practice an important rite of passage, which is a prerequisite to family life. It is at the core of the Kisii life including, social relations, identity, marriage and its stability, sexuality, reproduction, responsibility, and development from girlhood to womanhood. These findings concur with other authors [16] [26] who note that FGC is closely associated with the control of sexuality and that the practice remains an important custom without which a Kisii girl may find it difficult to marry. However, data also suggest that as circumcised women advance in age their sexual desire is lowered, which may create a friction in marriage. Thus, while FGC has positive contributions to the social wellbeing of the community, it may also cause family instability thereby eroding the very cultural values it is intended to promote/safeguard.

The importance and demands of culture transcend gender, age, levels of education, and professional affiliation. The importance of culture notwithstanding, the chi-square test $\mathrm{p}<0.05$ shows that the association percentage increased slightly with the increase in the level of education and occupation.

However, there is evidence to suggest that even though the site of operation, the home, has not significantly changed, changes are taking place regarding who performs the operation. Health workers are increasingly participating in FGC, where they provide medicine to prevent infection and other complications such as excessive bleeding. Thus FGC has increasingly become medicalized. Medicalization of FGC is not unusual among other girls circumcising communities, for example, the Rendille of Northern Kenya ([15], pp. 121-122).

Female genital cut is associated with various health risks. Many of the respondents (63\%) had heard about the health risks, but the mentioned risks appear to be short term such as pain, difficult labor, excessive bleeding, and a possibility of infections with little or no knowledge of the long term health risks associated with the practice. Indeed, the respondents held that as long as the cut is done at the age of 10 years and below, and is performed by a health practitioner, the health risks associated with it are either minimal or are all together eliminated. In his work Gachiri (2002) noted that there are several health risks arising from FGC some of which are short term and others long term. From this study, the long term health risks such as the psychological and emotional effects or death did not seem to be a major concern of the informants.

The traditional birth attendants attributed any difficulties in child delivery not to circumcision but to the position of the foetus. One TBA reported, "generally we have not experienced any problem because of being circumcised... even those who give birth at home will have no difficulties so long as the baby is in the right position."

The foregoing notwithstanding, the current study indicates that only $23 \%$ were given medication when the cut was performed. Similarly, most (77\%) of the operations were done at home with only $17 \%$ performed in hospital. Interestingly, a big proportion (64\%) of FGC is said to be performed by medical personnel who also give medicine to the initiates. An earlier research among the Abagusii reported that female genital cut had become a business involving different cadres of health staff. According to this research [6] most of FGC is performed either by nurses or midwives.

Efforts to eradicate female genital cut are widely spread among the Abagusii with the overwhelming majority (93\%) having heard of campaigns against the practice. The campaigns focus on various issues and the community is given various reasons for its eradication among them the health risks, depresses sexual desire, government order, practice against biblical teachings, outdated practice. Generally, however, the community is less supportive of the campaigns to eradicate FGC probably because of the approach taken. This is attested to by the prevalence of the practice, which remains universal at $99 \%$ among the Kisii, implying that circumcision remains a highly valued custom.

\section{Conclusions}

The present study sought to discuss the value of FGC and the perceived attendant health risks among the Kisii of 
western Kenya. Available literature on FGC in Kenya shows that it is practised in all the eight provinces with varying degrees ranging from $1 \%$ in Western region to $98 \%$ in North Eastern region. The current study has shown that FGC is universal (99\%) among the Kisii and its value is varied with the main one being a rite of passage from girlhood to womanhood. This rite is accompanied by social training, which makes the girl fit in the Abagusii sociocultural system.

The Kisii are aware of the health risks associated with FGC. However, most of the perceived health risks such as excessive bleeding, pain, and the transmission of infections are short term all of which are considered surmountable through circumcision of the girls at an early age and by health professionals. Even though the site of operation has remained mainly the home rather than health care facility, in a sense, female genital cut in this community has been medicalized, which makes it a bit safe. There seems to be limited knowledge on the long term health risks associated with FGC including serious gynecological problems, emotional, and even death. Indeed, the cultural demands by far outweigh the health risks associated with the practice.

Many people have heard or know efforts that are being made to eradicate female genital cut. However, for these efforts to succeed there is need to address the sociocultural value of female genital cut in ways that are acceptable to the Kisii community, and by extension, other circumcising communities. Meanwhile, female circumcision remains a highly valued cultural institution among the Kisii and it is likely to continue.

\section{References}

[1] World Health Organization (1998) Female Genital Mutilation: An Overview. World Health Organization, Geneva.

[2] Gachiri, E.W. (2000) Female Circumcision, with Reference to the Agikuyu of Kenya. Paulines Publishers, Nairobi.

[3] World Health Organization (1997) Female Genital Mutilation: A Joint WHO/UNICEF/UNFPA Statement. World Health Organization, Geneva.

[4] Kenya National Bureau of Statistics (KNBS) and ICF Macro (2010) Kenya Demographic and Health Survey 20082009. KNBS and ICF Macro, Calverton.

[5] PATH/MYWO (2000) Final Evaluation Report on Eliminating the Practice of FGM: Awareness Raising and Community Change in Four Districts of Kenya. Maendeleo ya Wanawake Organization, Nairobi.

[6] Njue, C. and Askew, I. (2005) Medicalization of Female Genital Cutting among the Abagusii in Nyanza Province. United States Agency for International Development, Nairobi.

[7] The United Nations (2014) The Universal Declaration of Human Rights (UDHR). The United Nations, New York. http://www.un.org/en/documents/udhr/

[8] The United Nations (2014) The Convention on the Elimination of All Forms of Discrimination against Women (CEDAW). The United Nations, New York. http://www.hrcr.org/docs/CEDAW/cedaw.html

[9] The United Nations (2014) Convention on the Rights of the Child (UNCRC). The United Nations, New York. https://www.unicef.org.au/Discover/What-we-do/Convention-on-the-Rights-of-the-Child/childfriendlycrc.aspx

[10] The United Nations (2014) The Declaration on the Elimination of Violence against Women. The United Nations, New York. http://www.un.org/documents/ga/res/48/a48r104.htm

[11] World Health Organization (2001) Female Genital Mutilation: A Student’s Manual. Department of Gender and Women Health, WHO, Geneva.

[12] World Health Organization (2001) Female Genital Mutilation Policy Guidelines for Nurses and Midwives. World Health Organization, Geneva.

[13] Government of Kenya (1999) National Plan of Action for the Elimination of FGM in Kenya 1999-2019. Ministry of Health, Nairobi.

[14] World Health Organization (1979) Seminar on Traditional Practices Affecting the Health of Women and Children, Khartoum, Sudan, 10-15 February 1979. World Health Regional Office for the Eastern Mediterranean, Alexandria.

[15] Shell-Duncan, B. and Hernlund, Y. (2001) Female "Circumcision" in Africa: Dimensions of the Practice and Debates. In: Shell-Duncan, B. and Hernlund, Y., Eds., Female Circumcision in Africa: Culture, Controversy, and Change, Lynne Rienners Publishers, Boulder, 1-40.

[16] Momanyi, D.M. (2001) Female Circumcision among the Abagusii People in Kenya. African Herald Publishing House, Kendu Bay.

[17] Olenja, J.M. (2002) A Situation Analysis on the Status of Female Genital Mutilation Eradication in Kenya: A Literature Review. National Focal Point on FGM, Nairobi.

[18] Akama, J.S. and Maxon, R. (2006) Ethnography of the Gusii of Western Kenya: A Vanishing Cultural Heritage. Edwin 
Mellen Press, New York.

[19] Gwako, E.L.M. (1995) Continuity and Change in the Practice of Clitoridectomy in Kenya: A Case-Study of Abagusii. Journal of Modern African Studies, 33, 333-337. http://dx.doi.org/10.1017/S0022278X00021108

[20] Ahmadu, F. (2001) Rites and Wrongs: An Insider/Outsider Reflects on Power and Excision. In: Shell-Duncan, B. and Hernlund, Y., Eds., Female "Circumcision” in Africa: Culture, Controversy and Change, Lynne Rienner Publishers, Boulder, 283-312.

[21] Standard Team (2004) Traditional Circumcisers Taken to Court. The East Africa Standard.

[22] Edward, K. and Peter, N. (2006) Suspect Held as Two Girls Die after the Cut. The Daily Nation.

[23] Mose, G.B. (1997) Abagusii Female Circumcision and Its Impact on Women’s Role in Society. M.A. Dissertation, Nairobi University, Nairobi.

[24] Government of Kenya (2002) Kisii Central District Development Plan (2002-2008). Ministry of Finance and Planning, Nairobi. By GOK 2002.

[25] Kenya National Bureau of Statistics (2010) The 2009 Population and Housing Census. Vol. 1, Government Printer, Nairobi.

[26] Silberschmidt, M. (1999) Women Forget that Men Are the Masters: Gender Antagonism and Socio-Economic Change in Kisii District, Kenya. Nordiska Afrikainstitutet, German. 
Scientific Research Publishing (SCIRP) is one of the largest Open Access journal publishers. It is currently publishing more than 200 open access, online, peer-reviewed journals covering a wide range of academic disciplines. SCIRP serves the worldwide academic communities and contributes to the progress and application of science with its publication.

Other selected journals from SCIRP are listed as below. Submit your manuscript to us via either submit@scirp.org or Online Submission Portal.
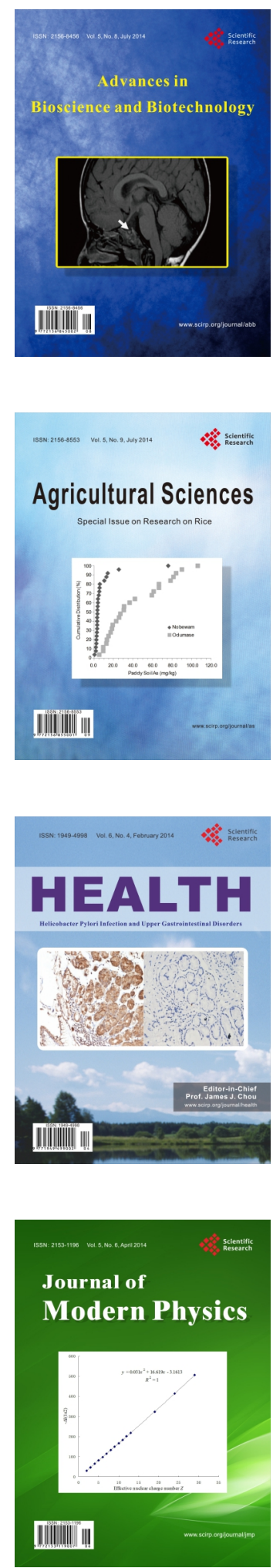
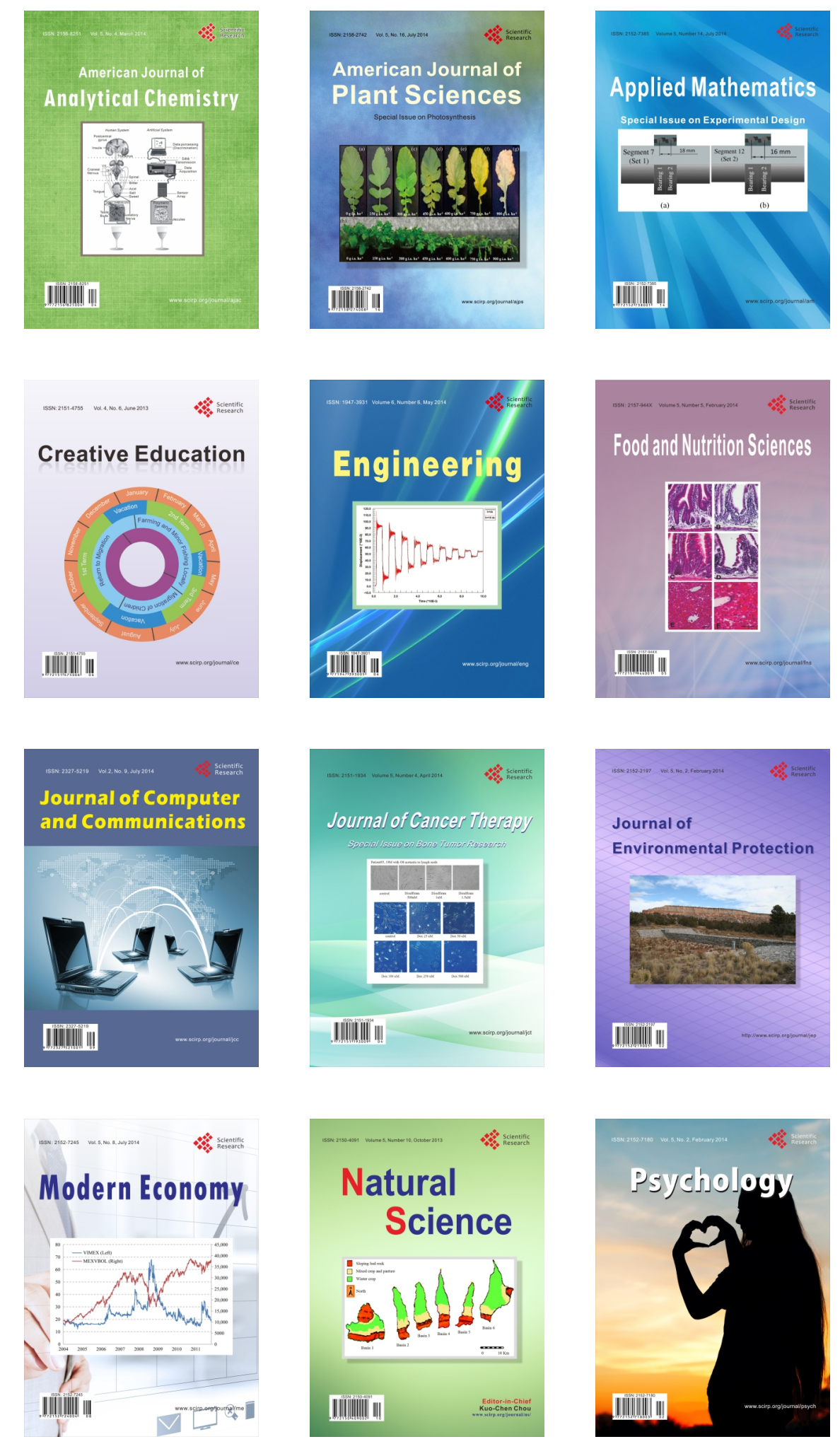